\title{
Variation in number of cagA EPIYA-C phosphorylation motifs between cultured Helicobacter pylori and biopsy strain DNA.
}

\author{
Anneli Karlsson, Anna Ryberg, Marjan Nosouhi Dehnoei, \\ Kurt Borch and Hans-Jürg Monstein
}

\section{Linköping University Post Print}

N.B.: When citing this work, cite the original article.

Original Publication:

Anneli Karlsson, Anna Ryberg, Marjan Nosouhi Dehnoei, Kurt Borch and Hans-Jürg Monstein, Variation in number of cagA EPIYA-C phosphorylation motifs between cultured Helicobacter pylori and biopsy strain DNA., 2011, Infection, Genetics and Evolution, epub ahead of print.

http://dx.doi.org/10.1016/j.meegid.2011.10.025

Copyright: Elsevier

http://www.elsevier.com/

Postprint available at: Linköping University Electronic Press

http://urn.kb.se/resolve?urn=urn:nbn:se:liu:diva-72456 


\section{Variation in number of $\operatorname{cag} A$ EPIYA-C phosphorylation motifs between cultured Helicobacter pylori and biopsy strain DNA}

Anneli Karlsson ${ }^{1}$, Anna Ryberg ${ }^{2}$, Marjan Nosouhi Dehnoei ${ }^{2}$, Kurt Borch ${ }^{3}$, Hans-Jürg Monstein $^{2^{*}}$

${ }^{1}$ Division of Surgery, Department of Clinical and Experimental Medicine, Faculty of Health Sciences, Linköping University, S-581 85 Linköping, Sweden

${ }^{2}$ Division of Clinical Microbiology, Department of Clinical and Experimental Medicine, Faculty of Health Sciences, Linköping University, Department of Clinical Microbiology, County Council of Östergötland, S-581 85 Linköping, Sweden

${ }^{3}$ Division of Surgery, Department of Clinical and Experimental Medicine, Faculty of Health Sciences, Linköping University, Division of Surgery, County Council of Östergötland, S-581 85 Linköping, Sweden

Article type: Short communication

Keywords: Gastroduodenal diseases, H. pylori, cagA EPIYA-C motif variation, gastric biopsy $H$. pylori strains, cultured H. pylori strains, amplicon sequencing, capillary gel electrophoresis.

*Corresponding author:

E-mail address: hans-jurg.monstein@liu.se

Telephone: +46 (0)131032475

Fax: +46 (0)131034596 


\begin{abstract}
The Helicobacter pylori cagA gene encodes a cytotoxin which is activated by phosphorylation after entering the host epithelial cell. Phosphorylation occurs on specific tyrosine residues within EPIYA motifs in the variable 3'-region. Four different cagA EPIYA motifs have been defined according to the surrounding amino acid sequence; EPIYA-A, -B, $\mathrm{C}$ and -D. Commonly, EPIYA-A and -B are followed by one or more EPIYA-C or -D motif. Due to observed discrepancies in cagA genotypes in cultured $H$. pylori and the corresponding DNA extracts it has been suggested that genotyping assays preferentially should be performed directly on DNA isolated from biopsy specimens. Gastric biopsies randomly selected from a Swedish cohort were homogenised and used for both direct DNA isolation and for H. pylori specific culturing and subsequent DNA isolation. In 123 of 153 biopsy specimens, the cagA EPIYA genotypes were in agreement with the corresponding cultured $H$. pylori strains. A higher proportion of mixed $\operatorname{cagA}$ EPIYA genotypes were found in the remaining 30 biopsy specimens. Cloning and sequencing of selected cagA EPIYA amplicons revealed variations in number of cagA EPIYA-C motifs in the mixed amplicons. The study demonstrates that culturing of $H$. pylori introduces a bias in the number of EPIYA-C motif. Consistent with other H. pylori virulence genotyping studies, we suggest that cagA EPIYA analysis should be performed using total DNA isolated from biopsy specimens.
\end{abstract}




\section{Introduction}

Helicobacter pylori is a microaerophilic Gram-negative bacterium that chronically infects the gastric mucosa. It is recognised as a human pathogen associated not only with chronic gastritis (Marshall and Warren, 1984), but also with peptic ulcer (Cover and Blaser, 1992) and gastric cancer (Parsonnet et al., 1991). Initially, classification of H. pylori was based on the combination of morphological and biochemical characteristics and growth requirements (Marshall and Warren, 1984). Genetic criteria have become increasingly important in the identification and characterisation of $H$. pylori. The cagA gene is a commonly used molecular marker of H. pylori virulence (Oleastro et al., 2009; van Doorn et al., 1998). The CagA cytotoxin is directly injected into epithelial cells via a type IV secretion system (Akopyants et al., 1998; Covacci et al., 1993; Yamazaki et al., 2003). In the host cell, CagA localises to the plasma membrane and undergoes phosphorylation on specific tyrosine residues within repeating penta amino acid Glu-Pro-Ile-Tyr-Ala (EPIYA) motifs, present at the C-terminus of the protein (Backert et al., 2001; Hatakeyama, 2003; Higashi et al., 2002). The 3'-end region of $\operatorname{cag} A$ where the tyrosine phosphorylation sites are located are highly polymorphic (Covacci et al., 1993; Tummuru et al., 1993; Yamaoka et al., 1998; Yamazaki et al., 2005). Four different CagA EPIYA motifs, EPIYA-A, -B, -C, and -D, have been defined based on the amino acid sequences surrounding the EPIYA residue (Higashi et al., 2002; Jones et al., 2009; Panayotopoulou et al., 2007; Sgouras et al., 2009; Yamazaki et al., 2005). CagA proteins nearly always possess an EPIYA-A and an EPIYA-B, followed by various number of EPIYAC repeats in Western-type (Yamazaki et al., 2005) or EPIYA-D motifs in East Asian type strains (Panayotopoulou et al., 2007; Sgouras et al., 2009). It has been suggested that the considerable variation in number of repeating EPIYA-C or -D motifs determines the biological activity of CagA in phosphorylation-dependent as well as phosphorylationindependent ways (Costa et al., 2009; Higashi et al., 2002). Furthermore, it has been shown 
that the number of CagA EPIYA-C motifs is an important risk factor for cancer among Western strains (Basso et al., 2008; Batista et al., 2011). A high number of $H$. pylori CagA EPIYA-C phosphorylation sites increase the risk of gastric cancer, but not duodenal ulcer (Basso et al., 2008; Batista et al., 2011; Chuang et al., 2011), and Batista and co-workers further showed that mixed strain infection was significantly more frequent in patients with gastric cancer than in those with gastritis.

Most studies on the $H$. pylori cagA gene have been carried out on DNA isolated from cultured H. pylori isolates or from mucosal biopsy specimens (Fujimoto et al., 1994; Gunn et al., 1998; Lopez-Vidal et al., 2008; Morales-Espinosa et al., 1999; Yamaoka et al., 1998). Different PCR-based assays have been described for molecular typing of EPIYA phosphorylation motifs both in gastric biopsy specimens (Gunn et al., 1998; Monstein et al., 2010; Rota et al., 2001) and in co-cultured H. pylori isolates (Argent et al., 2005). Some studies established a correlation between genotypes and disease outcome, while other studies did not (Acosta et al., 2010; Ahmad et al., 2009; Sgouras et al., 2009; Shokrzadeh et al., 2009). The question arises whether the choice of different PCR-based assays used in the various studies contributes to the inconsistent results, or if other factors may contribute to the result outcome. One such factor may be the occurrence of mutations, selection of a single strain from a sample containing mixed strains, or both, when culturing $H$. pylori strains (Kraft and Suerbaum, 2005; Marshall et al., 1998). It is still debated whether or not molecular genotyping of $\operatorname{cagA}$ should be performed on cultured H. pylori strains or biopsy DNA (Gunn et al., 1998; Kim et al., 2009; Park et al., 2003).

Herein, we compare the number of cagA EPIYA genotypes between 153 biopsy total DNA and the corresponding DNA isolated from cultured $H$. pylori strains using a recently described improved PCR-based strategy (Monstein et al., 2010; Ryberg et al., 2008). 


\section{Materials and methods}

\subsection{Study subjects and tissue collection}

Frozen $\left(-80^{\circ}\right.$ C) gastric biopsy specimens from a gastroscopic screening study in a randomly selected cohort of the population of Linköping, Sweden (Borch et al., 2000), were used. The study was approved by the local ethical committee in Linköping, Sweden (Dnr. 98007) and conducted in accordance with the Helsinki declaration. From this cohort, 71 individuals with $H$. pylori infection were selected and gastroscopic biopsies from antrum, corpus or bulbus duodeni were analysed. A total of 153 gastric biopsy specimens from 71 individuals (59 corpus, 57 antrum, 37 bulbus duodeni) were homogenized by grinding. For 51 of the individuals, biopsies from more than one location were included. The homogenates were then divided into two parts. Approximately one part was used for direct automated DNA isolation and whole genome amplification by means of multiple displacement amplification (MDA), generating total MDA-DNA (cellular and bacterial DNA), using a Illustra GenomiPhi V2 DNA kit (GE-Healthcare, Uppsala, Sweden) according to the manufacturer's instruction. The other part of the homogenate was used for bacterial culturing using established clinical routine procedures (Redeen et al., 2011). Subsequent, bacterial DNA was extracted, followed by multiple displacement amplification generating H. pylori MDA-DNA (providing equal genotyping conditions for biopsy and cultured $H$. pylori strain derived DNA). In both cases, DNA was isolated using the BioRobot M48 and MagAttract DNA Mini M48 kit following the manufacturer's instruction (Qiagen, Hilden, Germany).

\section{2 cagA EPIYA motif sequence analysis.}

The $3^{\prime}$-end of the $\operatorname{cagA}$ gene encoding the EPIYA motifs, was amplified using MDA-DNA derived from biopsy specimens and cultured H. pylori strains. Primers used were M13cagA.epiya.SE (TGT AAA ACG ACG GCC AGT CCC TAG TCG GTA ATG GRT TRT CT) 
and T7-cagA.epiya.AS (TAA TAC GAC TCA CTA TAG GGT GTG GCT GTT AGT AGC GTA ATT GTC) (Monstein et al., 2010), tagged with a universal M13 uni (-21) or T7 sequence, respectively (in italics). PCR was performed in a final reaction volume of $20 \mu$, including 10 pmol of each primer, $1 \mu \mathrm{l}$ of MDA-DNA, and 1x HotStarTaq Master mix (Qiagen, Hilden, Germany) using PCR conditions as follows: $95^{\circ} \mathrm{C}$ for $15 \mathrm{~min} ; 30$ cycles of $95^{\circ} \mathrm{C}$ for $20 \mathrm{~s}$, $55^{\circ} \mathrm{C}$ for $20 \mathrm{~s}, 72^{\circ} \mathrm{C}$ for $40 \mathrm{~s}$; and final extension at $72^{\circ} \mathrm{C}$ for $10 \mathrm{~min}$. Prior to DNA sequence analysis, amplicons were analysed by capillary gel electrophoresis (CGE) using a QIAxcel system and a QIAxcel DNA Screening kit (Qiagen, Hilden, Germany). The cagA EPIYA amplicons were sequenced using a M13 uni (-21) sequencing primer at a customer sequencing service (Eurofins MWG Operon, Ebersberg, Germany). The obtained DNA sequences were analysed using the CLC Bioinformatics DNA Workbench version 5.5 (CLC-Bio, http://www.clcbio.com). CagA empty site was verified as described previously (Monstein et al., 2010).

\subsection{Cloning and sequence analysis of cagA amplicons}

Amplicons derived from MDA-DNA of five biopsies (Nos. 125C, 242C, 310C, 346A, 346C) (Table 3) were selected and cloned using a TOPO-TA cloning kit (pCR 2.1-TOPO vector) according to the protocol (Invitrogen, Carlsbad, USA). One to ten white colonies of each isolate were picked and used directly in a confirmatory cagA EPIYA PCR amplification assay as described above. The amplicons were sequenced using M13-cagA.epiya.SE (described in section 2.2) as sequencing primer at a custom sequencing service (Eurofins MWG Operon).

\section{$2.416 S$ rDNA Pyrosequencing analysis}

For detection and verification of the presence of $H$. pylori DNA, the $16 \mathrm{~S}$ rDNA variable 
V3 region was amplified using primers bHJ.HP.JBS.V3.SE (Biotin-CCT AGG CTT GAC ATT GAN AGA A) and B-V3.AS (ACG ACA GCC ATG CAG CAC CT). PCR amplification was performed in the same concentrations and conditions as described in section 2.2. Prior to sequencing, amplicons were analyzed by CGE using QIAxcel DNA High Resolution kit (Qiagen, Hilden, Germany). Pyrosequencing was carried out using a PyroMark Gold Q24 kit following the manufacturer's instruction (Qiagen, Hilden, Germany). Obtained DNA sequences were aligned and compared with catalogued $H$. pylori 26695 [GenBank:NC000915], H. pylori J99 [GenBank:AE001439], H. pylori Shi470 [GeneBank:CP001072], and H. pylori P12 [GeneBank:CP001217] sequences using the CLC Bioinformatics DNA workbench version 5.5 (CLC-Bio, http://www.clcbio.com).

\section{Results}

\subsection{Overall comparison between biopsy DNA and cultured $H$. pylori results}

A total of 153 gastric biopsy specimens from 71 individuals were investigated for cagA EPIYA genotypes. 123 of the samples revealed equal cagA genotypes between biopsy MDADNA and the corresponding cultured $H$. pylori MDA-DNA. Multiple (two or more) cagA EPIYA amplicons of different sizes were detected in 16 of these 123 biopsies (Table 1; Figure 1). DNA sequencing of the single amplicons revealed the presence of different cagA EPIYA motifs; EPIYA-ABC in 52, -ABCC in $23,-A B C C C$ in one, $-A B$ in two, $-A C$ in one, $-A C C$ in one, and -AABC in one of the 123 samples. In 26 biopsies, no cagA amplicons were generated, which was verified by cagA empty site PCR (Table 1).

\subsection{Variations between biopsy DNA and cultured H. pylori}

CGE and sequencing of amplicons derived from biopsy MDA-DNA and the corresponding 


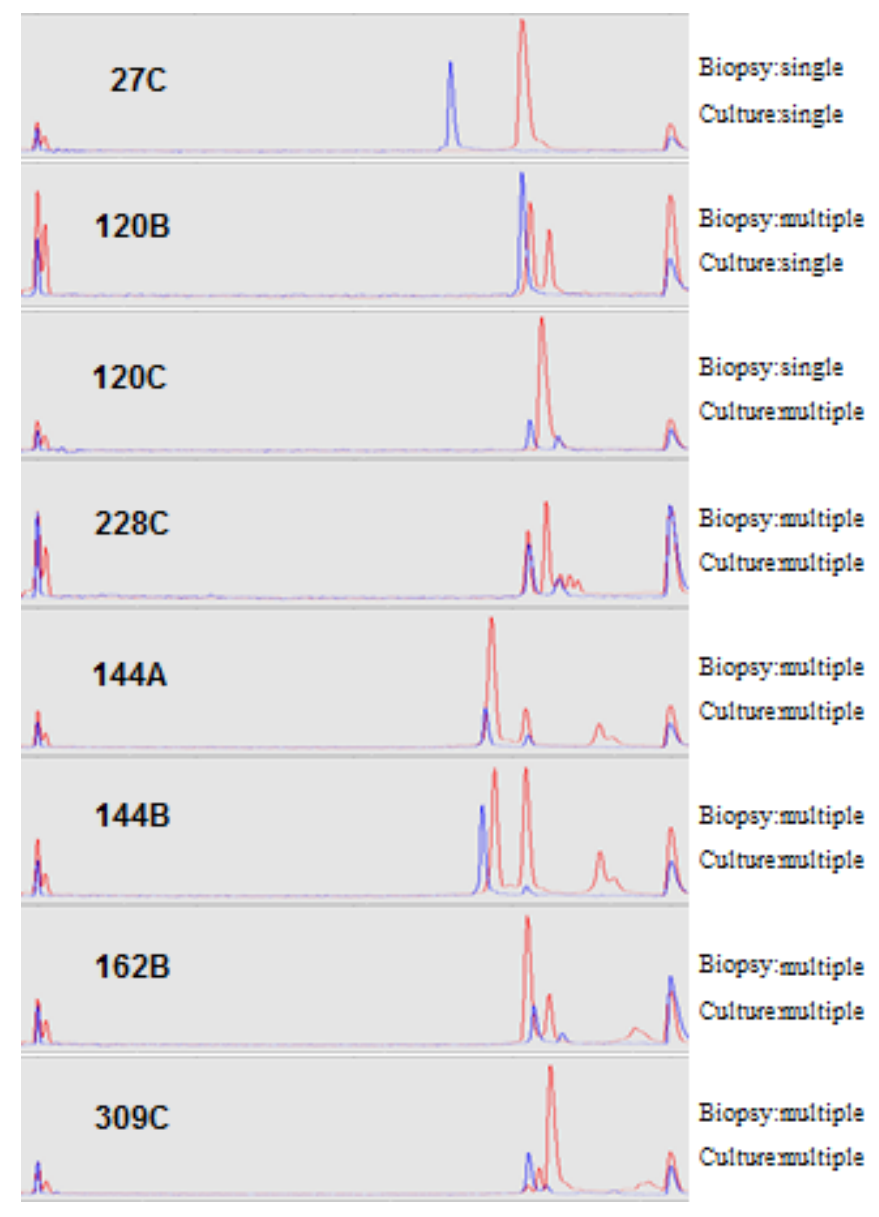

\section{Figure 1}

Superimposed electropherograms of cagA EPIYA amplicons with diverging amplicon patterns derived from DNA isolated from eight selected gastric biopsy samples (red), and from DNA isolated from the corresponding H. pylori cultures (blue). First and last peak in each electropherogram indicates internal alignment markers. Each peak between the alignment markers indicates the presence of one cagA EPIYA genotype. Although multiple cagA EPIYA amplicons were detected in biopsy total DNA and the corresponding DNA isolated from cultured $H$. pylori strains, in five of the eight samples (228C, 144A, 144B, 162B, 309C) the size pattern for each amplicon mix was unique. Single = one amplicon; multiple $=$ two or more amplicons.

cultured H. pylori MDA-DNA revealed different cagA EPIYA genotypes in 30 of 153 biopsies. In these 30 biopsies, multiple cagA EPIYA amplicons were observed in 21 of the biopsy MDA-DNA, whereas the corresponding cultured $H$. pylori MDA-DNA revealed single amplicons of cagA EPIYA -AB, - $\mathrm{ABC}$ or -ABCC genotypes (Table 2). Two of the 30 biopsy MDA-DNA samples (Nos. 120C and 290C) yielded single amplicons of cagA EPIYA-ABCC 
genotype (Table 2), whereas the corresponding cultured H. pylori MDA-DNA yielded multiple amplicons. In one sample (No. 152A), multiple amplicons were generated using biopsy MDA-DNA, however no amplicon was generated using MDA-DNA derived from the corresponding cultured $H$. pylori MDA-DNA. In five biopsies (144A, 144B, 162B, 228C and 309C), both biopsy MDA-DNA and the corresponding cultured H. pylori MDA-DNA displayed multiple amplicons with different size patterns (Figure 1; Table 2).

\subsection{Cloning and sequence analysis of selected mixed amplicons derived from biopsy DNA}

Cloning of five selected samples with multiple amplicons (gastric biopsy DNA Nos. 125C, 242A, 310C, 346A, 346C) and subsequent sequencing confirmed considerable variations in the number of EPIYA-C motifs within each sample (Table 3). In one case (sample no. 310C), five different cagA EPIYA-C genotypes (ABCC, $\mathrm{ABCCC}, \mathrm{ABCCCC}, \mathrm{ABCCCCC}$ and ABCCCCCC) were identified (Table 3). Similar variations in the number of EPIYA-C motifs were observed in the other cloned amplicons. Only one cagA EPIYA-ABCC genotype could be established from cultured H. pylori isolate No. 242A, since cloning of the amplicon yielded only one colony (Table 3).

\subsection{S rDNA Pyrosequencing}

$16 \mathrm{~S}$ rDNA pyrosequencing revealed the presence of $H$. pylori DNA in all biopsy specimens. DNA sequence comparison with catalogued sequences revealed the presence of 16S rDNA V3 sequences corresponding to H. pylori 26695 in 80 of 153, H. pylori J99 in 28 of 153, H. pylori 26695/J99 in 34 of 153, and H. pylori strain A in 9 of 153 biopsy specimens. In one biopsy each (Nos. $71 \mathrm{C}$ and $75 \mathrm{C}$ ), the pyrogram revealed the presence of two $16 \mathrm{~S}$ rDNA V3 motifs corresponding to H. pylori 26695 and 26695/J99, and 26695 and J99, respectively. 


\section{Discussion}

Mutation and recombination occurring in the $H$. pylori genome are considered to be responsible for generating strain diversity (Kraft and Suerbaum, 2005). In this view, it is assumed that founder strains of $H$. pylori, which initially colonize the gastric mucosa, undergo microevolution of their genome structure over a relative short period of time, generating $H$. pylori strains with highly similar genomes that display minor genetic differences (Carroll et al., 2004; Marshall et al., 1998). The general view is that microevolution occurs in most, if not all $H$. pylori strains. Therefore, it is conceivable that adaptation over time of individual $H$. pylori strains to different environmental conditions (biopsy specimen vs. cultured strains) may in part be responsible for the observed discrepancies reported in associating bacterial genotypes to diseases. Furthermore, a recent study has revealed that adaptive evolution may occur especially in host interaction genes, such as the $\operatorname{cag} A$, resulting in proteome diversification (Kawai et al., 2011).

It has been discussed that PCR-based genotyping directly from biopsy specimens tend to underestimate the prevalence of $H$. pylori specific virulence genes (Park et al., 2003; Secka et al., 2011). This may be due to limited access of $H$. pylori DNA, inhibition of PCR amplification due to high level of cellular genomic DNA, other PCR inhibitors or potent nucleases in gastric biopsy specimens (Monstein et al., 2005; Park et al., 2003; Thoreson et al., 1999). Whole genome amplification by multiple displacement amplification (MDA) can be used as a pre-PCR amplification step under conditions where PCR amplifications normally are hampered due to presence of inhibitors (Gonzalez et al., 2005) or where the amount of DNA is not sufficient for analysis (Ryberg et al., 2008). In this view, our previous and present studies have shown that PCR using MDA-DNA derived from biopsy DNA provides a reliable source for multiple molecular genotyping analysis (Monstein et al., 2010; Ryberg et al., 2008) 
In this study, the majority of the cultured H. pylori cagA EPIYA-C genotypes corresponded with the biopsy genotypes, but discrepancies were observed in 30 of the 153 biopsies (20\%; table 2). Similarly, Kim and co-workers showed that the inconsistent cagA genotyping results between cultured H. pylori strain DNA and biopsy DNA were $16 \%$ (Kim et al., 2009).

Different methodological approaches using either biopsy DNA or cultured strains to verify the presence of mixed H. pylori strains have shown conflicting results (Batista et al., 2011). Secka and co-workers have suggested that both biopsy DNA and cultured $H$. pylori should be analysed concomitantly (Secka et al., 2011). Park and co-workers have suggested that studies identifying associations between virulence factors and disease outcome should be restricted to sites with rare mixed $H$. pylori strain infection. However, this might lead to false perception of the actual relationship of bacterial strains and disease outcome (Park et al., 2003). Furthermore, they observed a higher proportion of mixed H. pylori strain infection in biopsy specimens (27\%) compared to cultured H. pylori strains (9\%) (Park et al., 2003). Similarly, based on $\operatorname{cagA}$ EPIYA genotyping we detected a higher proportion of mixed H. pylori strains in biopsy specimens (24\%) compared to cultured H. pylori strains (11\%). Cloning of cagA amplicons and subsequent sequence analysis was able to provide further information concerning the variation of $\operatorname{cagA}$ EPIYA genotypes. None of the methods described provided information whether or not the genotype variations were due to mixed $H$. pylori strain infection or arise within the stomach from an ancestor $H$. pylori strain as suggested in an early study by Yamaoka and co-workers (Yamaoka et al., 1999).

In view of a recent study (Sheu et al., 2009) where it was suggested that $H$. pylori infection at different sites of the stomach in the same patient could change the histological features in the antrum and the corpus, establishing of a correct number of cagA EPIYA-C motifs appears 
to be crucial for assessing links between $H$. pylori strains and gastroduodenal diseases. However, it is still not known whether or not certain threshold concentrations of individual $H$. pylori strains (quantitation) present in biopsy specimens have an impact on the disease outcome. Consequently, we believe that it is important to genotype all H. pylori strain variations present in a biopsy specimen. So far, molecular biology based methods do not allow for an unequivocal discrimination between mixed $H$. pylori strain infection or infection with an H. pylori founder strain undergoing microevolution (Carroll et al., 2004; Kraft and Suerbaum, 2005; Marshall et al., 1998). Consistently with other studies, we recommend that molecular typing of total DNA (human and bacterial DNA) isolated directly from biopsy specimens should be performed. Moreover, the improved PCR-based strategy provides a promising tool for high throughput molecular typing of $H$. pylori strains in a clinical routine microbiology laboratory.

\section{Competing interests}

The authors declare that they have no competing interests.

\section{Authors' contributions}

$\mathrm{AK}, \mathrm{AR}, \mathrm{MND}, \mathrm{KB}, \mathrm{HJM}$ participated in the conception, design, data interpretation and drafting of the manuscript. AK, AR, MND performed molecular genotyping. KB collected and selected the biopsy specimens. All authors have read and approved to the manuscript.

\section{Acknowledgments}

This study was supported by grants from the Research council in the South-East of Sweden (FORSS), the ALF-program, and the Molecular Biology Program at Clinical Microbiology, Laboratory Centre-DC, University Hospital, Linköping, Sweden. 


\section{References}

Acosta, N., Quiroga, A., Delgado, P., Bravo, M.M., Jaramillo, C., 2010. Helicobacter pylori CagA protein polymorphisms and their lack of association with pathogenesis. World $\mathrm{J}$ Gastroenterol 16, 3936-3943.

Ahmad, T., Sohail, K., Rizwan, M., Mukhtar, M., Bilal, R., Khanum, A., 2009. Prevalence of Helicobacter pylori pathogenicity-associated cagA and vacA genotypes among Pakistani dyspeptic patients. FEMS Immunol Med Microbiol 55, 34-38.

Akopyants, N.S., Clifton, S.W., Kersulyte, D., Crabtree, J.E., Youree, B.E., Reece, C.A., Bukanov, N.O., Drazek, E.S., Roe, B.A., Berg, D.E., 1998. Analyses of the cag pathogenicity island of Helicobacter pylori. Mol Microbiol 28, 37-53.

Argent, R.H., Zhang, Y., Atherton, J.C., 2005. Simple method for determination of the number of Helicobacter pylori CagA variable-region EPIYA tyrosine phosphorylation motifs by PCR. J Clin Microbiol 43, 791-795.

Backert, S., Moese, S., Selbach, M., Brinkmann, V., Meyer, T.F., 2001. Phosphorylation of tyrosine 972 of the Helicobacter pylori CagA protein is essential for induction of a scattering phenotype in gastric epithelial cells. Mol Microbiol 42, 631-644.

Basso, D., Zambon, C.F., Letley, D.P., Stranges, A., Marchet, A., Rhead, J.L., Schiavon, S., Guariso, G., Ceroti, M., Nitti, D., Rugge, M., Plebani, M., Atherton, J.C., 2008. Clinical relevance of Helicobacter pylori cagA and vacA gene polymorphisms. Gastroenterology 135, 91-99.

Batista, S.A., Rocha, G.A., Rocha, A.M., Saraiva, I.E., Cabral, M.M., Oliveira, R.C., Queiroz, D.M., 2011. Higher number of Helicobacter pylori CagA EPIYA C phosphorylation sites increases the risk of gastric cancer, but not duodenal ulcer. BMC Microbiol 11, 61.

Borch, K., Jonsson, K.A., Petersson, F., Redeen, S., Mardh, S., Franzen, L.E., 2000.

Prevalence of gastroduodenitis and Helicobacter pylori infection in a general population sample: relations to symptomatology and life-style. Dig Dis Sci 45, 1322-1329.

Carroll, I.M., Ahmed, N., Beesley, S.M., Khan, A.A., Ghousunnissa, S., Morain, C.A., Habibullah, C.M., Smyth, C.J., 2004. Microevolution between paired antral and paired antrum and corpus Helicobacter pylori isolates recovered from individual patients. J Med Microbiol 53, 669-677.

Chuang, C.H., Yang, H.B., Sheu, S.M., Hung, K.H., Wu, J.J., Cheng, H.C., Chang, W.L., Sheu, B.S., 2011. Helicobacter pylori with stronger intensity of CagA phosphorylation lead to an increased risk of gastric intestinal metaplasia and cancer. BMC Microbiol 11, 121.

Costa, A.C., Figueiredo, C., Touati, E., 2009. Pathogenesis of Helicobacter pylori infection. Helicobacter 14 Suppl 1, 15-20.

Covacci, A., Censini, S., Bugnoli, M., Petracca, R., Burroni, D., Macchia, G., Massone, A., Papini, E., Xiang, Z., Figura, N., et al., 1993. Molecular characterization of the 128-kDa immunodominant antigen of Helicobacter pylori associated with cytotoxicity and duodenal ulcer. Proc Natl Acad Sci U S A 90, 5791-5795. 
Cover, T.L., Blaser, M.J., 1992. Helicobacter pylori and gastroduodenal disease. Annu Rev Med 43, 135-145.

Fujimoto, S., Marshall, B., Blaser, M.J., 1994. PCR-based restriction fragment length polymorphism typing of Helicobacter pylori. J Clin Microbiol 32, 331-334.

Gonzalez, J.M., Portillo, M.C., Saiz-Jimenez, C., 2005. Multiple displacement amplification as a pre-polymerase chain reaction (pre-PCR) to process difficult to amplify samples and low copy number sequences from natural environments. Environ Microbiol 7, 1024-1028.

Gunn, M.C., Stephens, J.C., Stewart, J.D., Rathbone, B.J., 1998. Detection and typing of the virulence determinants cagA and vacA of Helicobacter pylori directly from biopsy DNA: are in vitro strains representative of in vivo strains? Eur J Gastroenterol Hepatol 10, 683-687.

Hatakeyama, M., 2003. Helicobacter pylori CagA--a potential bacterial oncoprotein that functionally mimics the mammalian Gab family of adaptor proteins. Microbes Infect 5, 143150.

Higashi, H., Tsutsumi, R., Fujita, A., Yamazaki, S., Asaka, M., Azuma, T., Hatakeyama, M., 2002. Biological activity of the Helicobacter pylori virulence factor CagA is determined by variation in the tyrosine phosphorylation sites. Proc Natl Acad Sci U S A 99, 14428-14433.

Jones, K.R., Joo, Y.M., Jang, S., Yoo, Y.J., Lee, H.S., Chung, I.S., Olsen, C.H., Whitmire, J.M., Merrell, D.S., Cha, J.H., 2009. Polymorphism in the CagA EPIYA motif impacts development of gastric cancer. J Clin Microbiol 47, 959-968.

Kawai, M., Furuta, Y., Yahara, K., Tsuru, T., Oshima, K., Handa, N., Takahashi, N., Yoshida, M., Azuma, T., Hattori, M., Uchiyama, I., Kobayashi, I., 2011. Evolution in an oncogenic bacterial species with extreme genome plasticity: Helicobacter pylori East Asian genomes. BMC Microbiology 11.

Kim, Y.S., Kim, N., Kim, J.M., Kim, M.S., Park, J.H., Lee, M.K., Lee, D.H., Kim, J.S., Jung, H.C., Song, I.S., 2009. Helicobacter pylori genotyping findings from multiple cultured isolates and mucosal biopsy specimens: strain diversities of Helicobacter pylori isolates in individual hosts. Eur J Gastroenterol Hepatol 21, 522-528.

Kraft, C., Suerbaum, S., 2005. Mutation and recombination in Helicobacter pylori: mechanisms and role in generating strain diversity. Int J Med Microbiol 295, 299-305.

Lopez-Vidal, Y., Ponce-de-Leon, S., Castillo-Rojas, G., Barreto-Zuniga, R., Torre-Delgadillo, A., 2008. High diversity of vacA and cagA Helicobacter pylori genotypes in patients with and without gastric cancer. PLoS One 3, e3849.

Marshall, B.J., Warren, J.R., 1984. Unidentified curved bacilli in the stomach of patients with gastritis and peptic ulceration. Lancet 1, 1311-1315.

Marshall, D.G., Dundon, W.G., Beesley, S.M., Smyth, C.J., 1998. Helicobacter pylori--a conundrum of genetic diversity. Microbiology 144 ( Pt 11), 2925-2939.

Monstein, H.J., Karlsson, A., Ryberg, A., Borch, K., 2010. Application of PCR amplicon sequencing using a single primer pair in PCR amplification to assess variations in 
Helicobacter pylori CagA EPIYA tyrosine phosphorylation motifs. BMC Res Notes 3, 35.

Monstein, H.J., Olsson, C., Nilsson, I., Grahn, N., Benoni, C., Ahrne, S., 2005. Multiple displacement amplification of DNA from human colon and rectum biopsies: bacterial profiling and identification of Helicobacter pylori-DNA by means of 16S rDNA-based TTGE and pyrosequencing analysis. J Microbiol Methods 63, 239-247.

Morales-Espinosa, R., Castillo-Rojas, G., Gonzalez-Valencia, G., Ponce de Leon, S., Cravioto, A., Atherton, J.C., Lopez-Vidal, Y., 1999. Colonization of Mexican patients by multiple Helicobacter pylori strains with different vacA and cagA genotypes. J Clin Microbiol 37, 3001-3004.

Oleastro, M., Cordeiro, R., Yamaoka, Y., Queiroz, D., Megraud, F., Monteiro, L., Menard, A., 2009. Disease association with two Helicobacter pylori duplicate outer membrane protein genes, homB and homA. Gut Pathog 1, 12.

Panayotopoulou, E.G., Sgouras, D.N., Papadakos, K., Kalliaropoulos, A., Papatheodoridis, G., Mentis, A.F., Archimandritis, A.J., 2007. Strategy to characterize the number and type of repeating EPIYA phosphorylation motifs in the carboxyl terminus of CagA protein in Helicobacter pylori clinical isolates. J Clin Microbiol 45, 488-495.

Park, C.Y., Kwak, M., Gutierrez, O., Graham, D.Y., Yamaoka, Y., 2003. Comparison of genotyping Helicobacter pylori directly from biopsy specimens and genotyping from bacterial cultures. J Clin Microbiol 41, 3336-3338.

Parsonnet, J., Friedman, G.D., Vandersteen, D.P., Chang, Y., Vogelman, J.H., Orentreich, N., Sibley, R.K., 1991. Helicobacter pylori infection and the risk of gastric carcinoma. N Engl J Med 325, 1127-1131.

Redeen, S., Petersson, F., Tornkrantz, E., Levander, H., Mardh, E., Borch, K., 2011. Reliability of Diagnostic Tests for Helicobacter pylori Infection. Gastroenterol Res Pract 2011, 940650.

Rota, C.A., Pereira-Lima, J.C., Blaya, C., Nardi, N.B., 2001. Consensus and variable region PCR analysis of Helicobacter pylori 3' region of cagA gene in isolates from individuals with or without peptic ulcer. J Clin Microbiol 39, 606-612.

Ryberg, A., Borch, K., Sun, Y.Q., Monstein, H.J., 2008. Concurrent genotyping of Helicobacter pylori virulence genes and human cytokine SNP sites using whole genome amplified DNA derived from minute amounts of gastric biopsy specimen DNA. BMC Microbiol 8, 175.

Secka, O., Antonio, M., Tapgun, M., Berg, D.E., Bottomley, C., Thomas, V., Walton, R., Corrah, T., Adegbola, R.A., Thomas, J.E., 2011. PCR-based genotyping of Helicobacter pylori of Gambian children and adults directly from biopsy specimens and bacterial cultures. Gut Pathog 3, 5.

Sgouras, D.N., Panayotopoulou, E.G., Papadakos, K., Martinez-Gonzalez, B., Roumbani, A., Panayiotou, J., vanVliet-Constantinidou, C., Mentis, A.F., Roma-Giannikou, E., 2009. CagA and VacA polymorphisms do not correlate with severity of histopathological lesions in Helicobacter pylori-infected Greek children. J Clin Microbiol 47, 2426-2434. 
Sheu, S.M., Sheu, B.S., Lu, C.C., Yang, H.B., Wu, J.J., 2009. Mixed infections of Helicobacter pylori: tissue tropism and histological significance. Clin Microbiol Infect 15, 253-259.

Shokrzadeh, L., Baghaei, K., Yamaoka, Y., Dabiri, H., Jafari, F., Sahebekhtiari, N., Tahami, A., Sugimoto, M., Zojaji, H., Zali, M.R., 2009. Analysis of 3'-end variable region of the cagA gene in Helicobacter pylori isolated from Iranian population. J Gastroenterol Hepatol 25, 172177.

Thoreson, A.C., Borre, M., Andersen, L.P., Jorgensen, F., Kiilerich, S., Scheibel, J., Rath, J., Krogfelt, K.A., 1999. Helicobacter pylori detection in human biopsies: a competitive PCR assay with internal control reveals false results. FEMS Immunol Med Microbiol 24, 201-208.

Tummuru, M.K., Cover, T.L., Blaser, M.J., 1993. Cloning and expression of a highmolecular-mass major antigen of Helicobacter pylori: evidence of linkage to cytotoxin production. Infect Immun 61, 1799-1809.

van Doorn, L.J., Figueiredo, C., Sanna, R., Plaisier, A., Schneeberger, P., de Boer, W., Quint, W., 1998. Clinical relevance of the cagA, vacA, and iceA status of Helicobacter pylori. Gastroenterology 115, 58-66.

Yamaoka, Y., El-Zimaity, H.M., Gutierrez, O., Figura, N., Kim, J.G., Kodama, T., Kashima, K., Graham, D.Y., 1999. Relationship between the cagA 3' repeat region of Helicobacter pylori, gastric histology, and susceptibility to low pH. Gastroenterology 117, 342-349.

Yamaoka, Y., Kodama, T., Kashima, K., Graham, D.Y., Sepulveda, A.R., 1998. Variants of the 3 ' region of the cagA gene in Helicobacter pylori isolates from patients with different $\mathrm{H}$. pylori-associated diseases. J Clin Microbiol 36, 2258-2263.

Yamazaki, S., Yamakawa, A., Ito, Y., Ohtani, M., Higashi, H., Hatakeyama, M., Azuma, T., 2003. The CagA protein of Helicobacter pylori is translocated into epithelial cells and binds to SHP-2 in human gastric mucosa. J Infect Dis 187, 334-337.

Yamazaki, S., Yamakawa, A., Okuda, T., Ohtani, M., Suto, H., Ito, Y., Yamazaki, Y., Keida, Y., Higashi, H., Hatakeyama, M., Azuma, T., 2005. Distinct diversity of vacA, cagA, and cagE genes of Helicobacter pylori associated with peptic ulcer in Japan. J Clin Microbiol 43, 3906-3916. 


\section{Tables}

Table 1. CagA EPIYA genotypes revealed in biopsies.

\begin{tabular}{|c|c|c|c|}
\hline \multirow{3}{*}{ CagA EPIYA } & \multirow{3}{*}{$\begin{array}{l}\text { No. of biopsy } \\
\text { specimens }\end{array}$} & \multirow{2}{*}{\multicolumn{2}{|c|}{$\begin{array}{c}\text { Results } \\
\text { (compared to culture) }\end{array}$}} \\
\hline & & & \\
\hline & & equal & not equal \\
\hline mixed strains & 37 & 16 & 21 \\
\hline$A B C$ & 55 & 52 & 3 \\
\hline$A B C C$ & 28 & 23 & 5 \\
\hline$A B C C C$ & 1 & 1 & \\
\hline$A B$ & 2 & 2 & \\
\hline AABC & 1 & 1 & \\
\hline$A A B C C$ & 1 & & 1 \\
\hline AC & 1 & 1 & \\
\hline ACC & 1 & 1 & \\
\hline empty site & 26 & 26 & \\
\hline
\end{tabular}

Table 2. CagA EPIYA genotype differences between biopsy and culture H. pylori DNA.

\begin{tabular}{|c|c|c|}
\hline \multirow{2}{*}{ Biopsy no. } & \multicolumn{2}{|c|}{ CagA EPIYA genotype } \\
\hline & biopsy & culture \\
\hline $346 \mathrm{~A}$ & mixed strains & $A B$ \\
\hline $1 \mathrm{~A}$ & mixed strains & $\mathrm{ABC}$ \\
\hline $110 \mathrm{C}$ & mixed strains & $\mathrm{ABC}$ \\
\hline $120 \mathrm{~B}$ & mixed strains & $\mathrm{ABC}$ \\
\hline $121 \mathrm{~A}$ & mixed strains & $\mathrm{ABC}$ \\
\hline $121 \mathrm{C}$ & mixed strains & $\mathrm{ABC}$ \\
\hline $154 \mathrm{C}$ & mixed strains & $\mathrm{ABC}$ \\
\hline $201 C$ & mixed strains & $\mathrm{ABC}$ \\
\hline $242 A$ & mixed strains & $\mathrm{ABC}$ \\
\hline $273 C$ & mixed strains & $\mathrm{ABC}$ \\
\hline $275 \mathrm{C}$ & mixed strains & $\mathrm{ABC}$ \\
\hline $281 \mathrm{~A}$ & mixed strains & $\mathrm{ABC}$ \\
\hline $346 C$ & mixed strains & $\mathrm{ABC}$ \\
\hline $26 \mathrm{C}$ & mixed strains & $\mathrm{ABCC}$ \\
\hline $125 \mathrm{~A}$ & mixed strains & $A B C C$ \\
\hline $125 \mathrm{C}$ & mixed strains & $A B C C$ \\
\hline $193 C$ & mixed strains & $A B C C$ \\
\hline $273 B$ & mixed strains & $A B C C$ \\
\hline $310 \mathrm{C}$ & mixed strains & $\mathrm{ABCC}$ \\
\hline $352 C$ & mixed strains & $A B C C$ \\
\hline $372 \mathrm{C}$ & mixed strains & $\mathrm{ABCC}$ \\
\hline $152 \mathrm{~A}$ & mixed strains & empty site \\
\hline $144 \mathrm{~A}$ & mixed strains ${ }^{b}$ & mixed strains ${ }^{b}$ \\
\hline $144 \mathrm{~B}$ & mixed strains ${ }^{b}$ & mixed strains ${ }^{b}$ \\
\hline $162 B$ & mixed strains ${ }^{b}$ & mixed strains ${ }^{b}$ \\
\hline $228 \mathrm{C}$ & mixed strains ${ }^{b}$ & mixed strains ${ }^{b}$ \\
\hline $309 C$ & mixed strains ${ }^{b}$ & mixed strains ${ }^{b}$ \\
\hline $120 \mathrm{C}$ & $\mathrm{ABCC}$ & mixed strains \\
\hline $290 \mathrm{C}$ & $\mathrm{ABCC}$ & mixed strains \\
\hline $27 \mathrm{C}$ & $\mathrm{ABC}$ & $\mathrm{AB}$ \\
\hline
\end{tabular}

${ }^{\mathrm{a}} \mathrm{A}$, antrum; $\mathrm{B}$, duodenum; $\mathrm{C}$, corpus

${ }^{b}$ both biopsy and culture contained multiple amplicons, however not identical size patterns 
(Figure 1).

Table 3. CagA EPIYA phenotypes deduced from sequencing of cloned amplicons.

\begin{tabular}{ccc}
\hline Biopsy no.. & Cloning of biopsy DNA & $\begin{array}{c}\text { Number of amplicons } \\
\text { disclosed by CGE }\end{array}$ \\
\hline $125 \mathrm{C}^{\mathrm{a}}$ & $\mathrm{ABCC}$ & 2 \\
\hline $242 \mathrm{~A}^{\mathrm{a}}$ & $\mathrm{ABCCCC}$ & 2 \\
& $\mathrm{ABC}$ & \\
$310 \mathrm{C}^{\mathrm{a}}$ & $\mathrm{ABCC}$ & 5 \\
& $\mathrm{ABCCC}$ & \\
& $\mathrm{ABCCCC}$ & 2 \\
\hline $346 \mathrm{~A}^{\mathrm{a}}$ & $\mathrm{ABCCCCC}$ & 2 \\
\hline $346 \mathrm{C}^{\mathrm{a}}$ & $\mathrm{ABCCCCCC}$ & 2 \\
\hline
\end{tabular}

${ }^{\mathrm{a}} \mathrm{A}$, antrum; C, corpus

${ }^{\mathrm{b}} \mathrm{CGE}$, capillary gel electrophoresis 